\title{
Opposing diel migration of fish and zooplankton in the littoral zone of a large lake
}

\author{
Andreas Lorke · Arnd Weber · Hilmar Hofmann • \\ Frank Peeters
}

\begin{abstract}
Backscatter data from an acoustic Doppler current profiler are analyzed to provide simultaneous estimates of relative concentration of Daphnia and relative abundance of young-of-the-year perch in the vicinity of an artificial reef in the littoral zone of Lake Constance. These long-term (3 months) and highresolution $(1 \mathrm{~h})$ observations demonstrate the existence of opposing diel migration patterns in fish and zooplankton. According to the data, the migration pattern constrains feeding of young-of-the-year fish on vertically migrating zooplankton to a few hours around sunrise and sunset. Temperature recorded simultaneously with the backscatter signal indicates that the diurnal activity pattern and the vertical distribution of the fish are not affected by strong temperature fluctuations generated by high-frequency internal wave motions. The abrupt decline of internal wave activity following a storm-induced deepening of the surface mixed layer, however, seems to be a trigger for changes in the diurnal activity and hence the intensity of predator-prey interactions.
\end{abstract}

Keywords Vertical migration . Acoustic backscatter · Zooplankton . Fish

Handling editor: S. I. Dodson

A. Lorke $(\bowtie) \cdot$ A. Weber $\cdot$ H. Hofmann $\cdot$ F. Peeters Limnological Institute, University of Konstanz, Mainaustrasse 252, 78464 Konstanz, Germany e-mail: Andreas.Lorke@uni-konstanz.de

\section{Introduction}

Understanding the temporal and the spatial dynamics of predator-prey interactions is one of the most important goals in aquatic ecology. The study of this rather complex dynamics, however, is often complicated by the heterogeneous distributions of predators and prey. The heterogeneous distribution of organisms is not only the result of external forcing parameters, such as physical factors or nutrient availability (see PinelAlloul (1995), Folt and Burns (1999), and Martin (2003) for recent reviews), but also the result of specific migration patterns. Diel vertical migration of zooplankton is a well-known phenomenon in lakes as well as in the ocean and is generally believed to be the result of a compromise between food availability for feeding and predator avoidance (Stich \& Lampert, 1981; Gliwicz, 1986; Lampert, 1993). The same reason is believed to trigger potential diel horizontal migration of zooplankton between the littoral and the pelagic zone in lakes (Davies, 1985; White, 1998; Burks et al., 2002).

Not only zooplankton but also fish as their main predators are looking for the same compromise between feeding and predatory pressure and were observed to perform diel migration (Wang \& Eckmann, 1994; Imbrock et al., 1996; Järvalt et al., 2005). In juvenile fish, in particular, this diurnal migration can be superimposed on a longer-term ontogenetic habitat shift. Long- and short-term migration patterns of fish and zooplankton affect their encounter rate and thus are crucial for an 
understanding of the interaction between the fish and the zooplankton.

Although such migration patterns and their determinants were studied in great detail for many different species and in a great variety of aquatic systems, combined observations of the spatio-temporal distributions of fish and zooplankton are rare (e.g., Ruiz et al., 1993; Hülsmann et al., 1999; Masson et al., 2001; Romare et al., 2003) and often limited by a rather coarse resolution. Such combined observations, however, are indispensable for an assessment of predator-prey interactions if both, predator and prey perform diel and potentially opposing migrations. Ongoing changes in trophic interactions in numerous large lakes, which are associated with re-oligotrophication, with the invasion of new species, or with a changing climate, provide a current need for studying predator-prey interactions under in-situ conditions.

In this article, we present acoustic observations of zooplankton and fish from the transition zone between the littoral and the pelagic zone of Lake Constance. The differential processing applied to acoustic backscatter data allows for simultaneous observations of zooplankton and fish concentration changes with a very high temporal resolution. Although the observations do not provide direct estimates of abundance or biomass, they can be used to investigate the spatial and temporal dynamics of zooplankton and fish distributions as well as their interactions, either by combining the observations with conventional sampling techniques, or by relating the observations to well-studied ecosystem characteristics. In this study, we will proceed along the latter way. The observations cover a period of about three months while providing a temporal resolution of one hour. Besides the temporal dynamics of predator (mainly young-of-the-year perch) and prey (mainly daphnids) concentrations, special emphasis was put on the impact of temperature fluctuations caused by high-frequency internal waves at the depth of the thermocline on the respective distribution dynamics.

\section{Measurements and analyses}

Study site and measurements

Lake Constance $\left(47^{\circ} \mathrm{N}, 9^{\circ} \mathrm{E}\right)$ is the second largest pre-alpine lake in Europe. It is a monomictic lake with a surface area of $536 \mathrm{~km}^{2}$ and a maximum depth of $254 \mathrm{~m}$, which is now in a phase of re-oligotrophication after it became eutrophic during the $1980 \mathrm{~s}$ (Gaedke, 1998).

The littoral zone, i.e., the zone that extends from the shoreline to the depth where sufficient light for plant growth reaches the bottom, comprises about $10 \%$ of the total surface area of Lake Constance. In order to concentrate fishes for commercial and sport fishing activities, artificial habitat structures are introduced at various locations in the littoral around the lake (Löffler, 1997). These structures are made of brushwood and boughs and have typical side lengths of about $10 \mathrm{~m}$ (Fig. 1). Such artificial reefs are not uncommon in lakes (Prince \& Maughan, 1978; Bassett, 1994; Rogers \& Bergersen, 1999), because they provide a complex habitat structure, which is used especially by small fish as a shelter for lowering their predation risk. Our study is based on measurements in the vicinity of an artificial reef, which is located nearby the Island of Mainau, at the southwestern shore of Lake Constance.

A $500 \mathrm{kHz}$ acoustic Doppler current profiler (NDP, NORTEK AS) was deployed upward-looking on a bottom-resting tripod at a depth of $12 \mathrm{~m}$, about $4 \mathrm{~m}$ in front of the artificial reef (Fig. 1). The NDP has three acoustic beams pointing into different directions which are inclined to the vertical by $20^{\circ}$ (Lorke \& Wüest, 2005). The instrument was set up to measure the three-dimensional current velocity and the received acoustic echo intensity from 64 depth cells with a vertical resolution (depth cell size) of $0.13 \mathrm{~m}$, resolving a range from 11.2 to $3 \mathrm{~m}$ depth. Depth cells (or bins) are uniform vertical segments of the NDPs profiling range over which the velocity and backscatter data are averaged. The lowest 10 depth

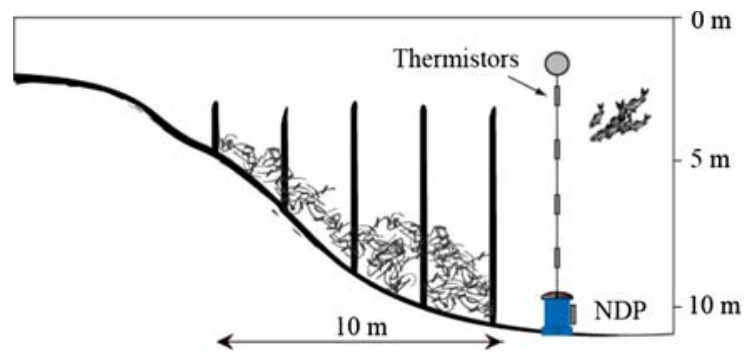

Fig. 1 Deployment design showing the Nortek Doppler profiler (NDP) and the thermistors at the lakefront of the artificial reef. The reef is made of wooden poles filled with brushwood and branches. (Figure is not to scale.) 
cells, however, were excluded from the subsequent analysis because of potential contamination of the measured echo intensity by ringing effects in the near-field of the acoustic transducers. The sampling frequency was set to $1 \mathrm{~Hz}$ and the instrument was deployed from August 18 until November 7, 2005. Failures in data recording resulted in two major data gaps of 8 and 3 consecutive days, respectively.

Six individual temperature loggers (TR-1050, RBR Ltd.) were deployed at 2, 4, 6, 8, 10, and $12 \mathrm{~m}$ depth above the NDP (Fig. 1). The sampling interval of the loggers was $10 \mathrm{~s}$ and the temperature resolution and accuracy are $\pm 5 \times 10^{-5}$ and $\pm 2 \times 10^{-3 \circ} \mathrm{C}$, respectively. Temperature recording stopped on October 21 due to battery depletion.

Plankton samples were collected at six particular days throughout the NDP deployment period (August 23 and 30, September 6 and 19, October 4 and 18) in central Lake Überlingen, a $140 \mathrm{~m}$ deep side-basin of Lake Constance. Crustacean zooplankton was sampled with a Clarke-Bumpus Sampler (mesh size $140 \mu \mathrm{m}$ ) by vertical hauls from $140 \mathrm{~m}$ depth. During routine measurements seven taxa were identified: Daphnia hyalina, Daphnia galeata, Bosmina sp., Eudiaptomus gracilis, cyclopoid copepods, Leptodora kindtii, and Bythotrephes longimanus (Straile \& Geller, 1998). The distance between the zooplankton sampling site and the NDP deployment site in the littoral zone is about $10 \mathrm{~km}$.

\section{Data analysis}

The echo intensity received from the 64 depth cells along the three beams was corrected for rangedependent losses of acoustic power due to absorption in water and beam spreading following Lorke et al. (2004). Although the instrument was not calibrated to provide correct absolute values of the resulting backscatter strength $S_{v}$ (in units of $\mathrm{dB}$ ), the magnitude of relative changes in $S_{v}$ is comparable to the calibrated output of scientific echo sounders.

Analysis of the resulting backscatter strength in terms of zooplankton concentrations and fish counts requires complementary techniques. Whereas individual fish creates distinct and strong echoes, zooplankton concentration is related to the volume backscattering strength forming the background signal. The presence of dense shoals of relatively small fishes and varying zooplankton concentrations, causing variations in the background levels of the backscatter strength, however, make the discrimination between the background signal and individual spikes more difficult and require some kind of temporal averaging.

As illustrated in Fig. 2, we were using a threshold value $S_{t h}$ of the backscatter strength and estimated fish counts $F_{N D P}$ for each profile and for each of the three individual beams by setting $F_{N D P}=1$ whenever $S_{t h}$ was exceeded and $F_{N D P}=0$ if not. $S_{t h}$ is not fixed, but is relative to the varying background level $S_{z o o}$ of the backscatter strength $\left(S_{t h}=S_{z o o}+20 \mathrm{~dB}\right) . S_{z o o}$ was estimated as the minimum backscatter strength observed at a particular depth during an averaging period of $1 \mathrm{~h}$. The motivation for this approach is that there was at least one profile within the averaging period where no fish was present in the respective depth cell. Fish counts $F_{N D P}$ are averaged over the three beams and the $1 \mathrm{~h}$ averaging period. Hence, $0 \leq F_{N D P} \leq 1$ and its magnitude can be considered as the probability that there were fishes within the sampling volume represented by the respective depth cells. A value of $F_{N D P}=1$ indicates that there were always fishes present within the averaging period.

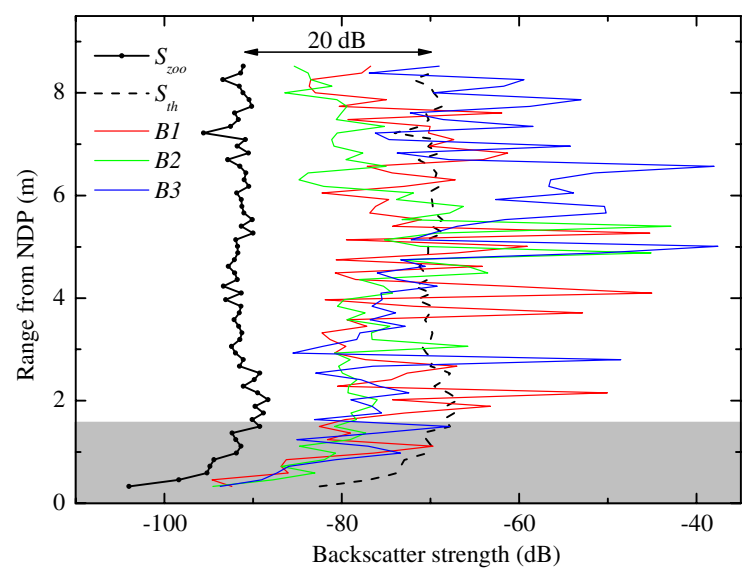

Fig. 2 Illustration of the fish-detection algorithm used for the NDP data. A minimum acoustic backscatter profile $\left(S_{z o o}\right)$ is estimated for the respective averaging period and a threshold profile $S_{t h}$ is defined as: $S_{t h}=S_{z o o}+20 \mathrm{~dB}$. Instantaneous backscatter values from the three individual beams $(B 1, B 2$, $B 3)$ exceeding this threshold are counted as one fish in the respective depth cell. Such individual counts are averaged over the three acoustic beams and over the averaging period of $1 \mathrm{~h}$. The grey area at the bottom indicates the near-field of the acoustic transducers, which was excluded from the subsequent analysis 
The quantitative interpretation of $F_{N D P}$ in terms of total abundance of fishes, however, is limited because we did not account for the magnitude of the backscatter spikes (fish echoes), which could be related to the presence of multiple fishes in the sampling volume. Throughout this study, we rather use $F_{N D P}$ as a qualitative indicator for the presence of fish.

The minimum backscatter strength in each hourly time segment, $S_{z o o}$, is considered as a qualitative estimate of the zooplankton concentration $C$, with $C \sim 10^{S_{z o o} / 10}$ ( $S_{z o o}$ in units of $\mathrm{dB}$, Lorke et al., 2004). By estimating $S_{z o o}$ as the minimum rather than the mean backscatter strength observed within the averaging period, we avoided a bias of the zooplankton concentration by frequent fish echoes. Changing concentrations of suspended sediments bias the zooplankton estimate $S_{z o o}$, but do not affect the fish counts $F_{N D P}$.

\section{Results}

The temperature dynamics, exemplified in Fig. 3a by the temperatures measured at $8 \mathrm{~m}$ and $4 \mathrm{~m}$ depth, is mainly characterized by a strong wind event on September 18, 2005 with wind speeds of up to $12 \mathrm{~m} \mathrm{~s}^{-1}$. Before this wind event, both thermistors were within the seasonal thermocline and showed strong temperature fluctuations of up to $10^{\circ} \mathrm{C}$ on time scales of minutes to hours, which were caused by internal waves (Lorke et al., 2006). Wind-induced mixing resulted in a deepening of the surface mixed layer, such that the thermocline was below the depth of measurement. As a consequence of the thermocline displacement, internal waves could not affect temperatures at the measuring depth after the wind event and amplitudes and frequencies of the temperature fluctuations were significantly reduced. This feature is even more pronounced in the standard deviation of the temperature estimated for the $1 \mathrm{~h}$ averaging period (Fig. 3b).

Complete time series of the estimated relative fish counts $F_{N D P}$ and acoustically determined zooplankton concentrations $S_{z o o}$ are shown in Fig. 3c and d, respectively. Similar to temperature, both estimates change their dynamics after the wind event. The high values observed during the actual storm are not considered here because they are most probably related to large concentrations of drifting material

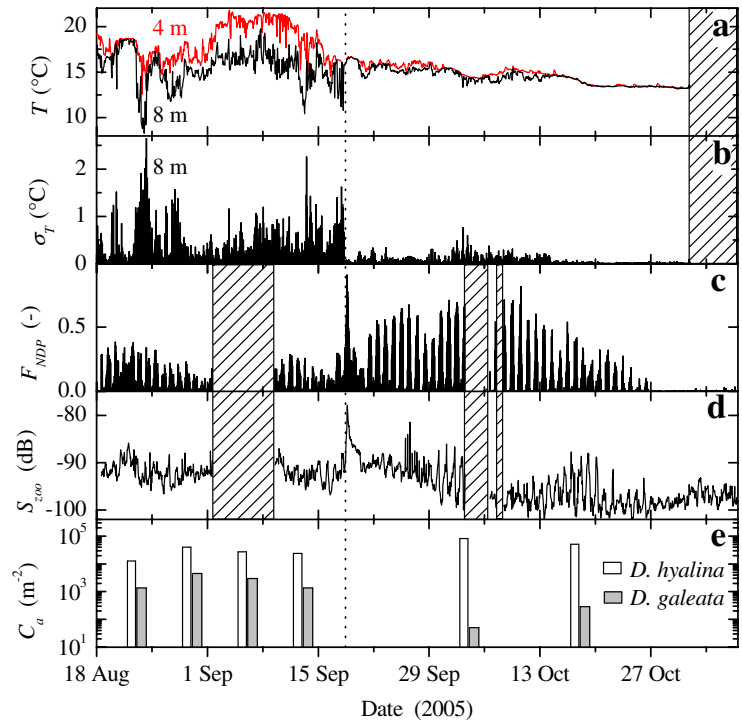

Fig. 3 (a) Time series of hourly averaged temperature $(T)$ measured at $8 \mathrm{~m}$ (black line) and at $4 \mathrm{~m}$ (red line) depth above the NDP. The standard deviation $\left(\sigma_{T}\right)$ of temperature at $8 \mathrm{~m}$ depth is shown in panel (b). (c) shows the depth-averaged relative fish abundance estimated from the $\mathrm{NDP}\left(F_{N D P}\right)$ and $(\mathbf{d})$ the depth-averaged background backscatter strength $S_{z o o}$, which is related to the zooplankton concentration. Data gaps are indicated by the hatched areas (panels a to d). Panel (e) shows the depth-integrated zooplankton concentrations $C_{a}$ of $D$. hyalina and D. galeata estimated from net hauls at a station in central Lake Überlingen. The timing of the wind event on September 18, 2005 is indicated by the dotted vertical line

and entrained air bubbles. Fish counts were well below 0.5 before September 18 but showed a pronounced diurnal pattern, whereby fishes could only be observed during daytime and no fish was present during the night. After the storm, the diurnal rhythm persisted, but relative fish counts increased gradually to maximum daytime values of $F_{N D P} \approx$ 0.8 at the beginning of October. Afterwards, the relative fish counts decreased again until October 26 and no fish was observed after that date.

A detailed view of the diurnal dynamics of $F_{N D P}$ is provided by Fig. 4. Note that the fish counts shown in Fig. 3c and 4 are depth-averaged. Hourly averages for individual depth cells can be as high as $F_{N D P} \approx 0.99$, indicating that fish were almost permanently present within those respective depth cells. The vertical distribution of fish is exemplified in Fig. $5 c$ and $5 d$ for time periods before and after the wind event. Fish counts were slightly increasing with decreasing depth before and were more homogeneously distributed after the storm. The diurnal 


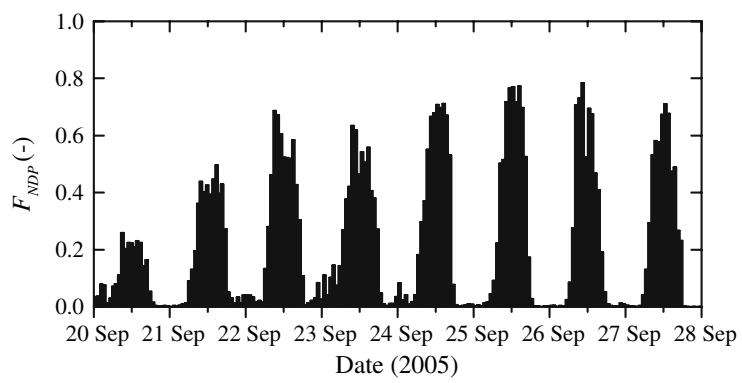

Fig. 4 Details of the depth-averaged relative fish abundance estimates from the NDP showing a strong diurnal pattern with high relative fish counts during daytime and no fish during the night (axis tick labels are at 00:00 h, respectively)

pattern, however, was present at all times and at all resolved depths. Fig. 5a and c further exemplify a time period of enhanced internal wave activity with a rapid increase in mean temperature and strong temperature fluctuations with amplitudes of up to $9^{\circ} \mathrm{C}$ on time scales of minutes, whereas temperature was nearly constant during the second time period shown in Fig $5 b$ and $d$.

Acoustically determined relative zooplankton concentrations were more or less constant before the wind event and did not show a pronounced diurnal pattern (Fig. 3c). After the wind event, the zooplankton concentration decreased gradually with time and, following September 29, started to show a diurnal migration pattern with high concentrations during night and low concentrations during daytime. The temporal migration pattern is hence reversed with respect to the diurnal pattern observed in the relative fish counts (Fig. 6).

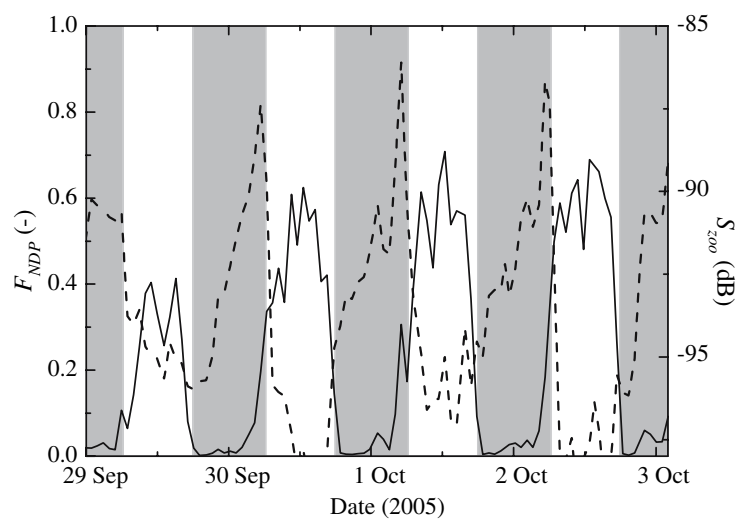

Fig. 6 Time series of the depth-averaged relative fish abundance $F_{N D P}$ (solid line) and of the depth-averaged relative zooplankton abundance $S_{z o o}$ (dashed line). Relative zooplankton abundance was estimated from the minimum backscatter profiles observed during the respective averaging period. The grey bars encompass the time period from dusk till dawn (local sunset and sun rise times). Note that the relative zooplankton estimate is given in logarithmic units, i.e., the observed increase of relative abundance of 10 corresponds to a concentration change of one order of magnitude

Sampled zooplankton densities of the dominant crustacean species $D$. hyalina and $D$. galeata at the pelagic station are shown in Fig. 3e. The absolute and relative abundance of both species was more or less constant before the wind event, whereas the abundance of $D$. hyalina was about one order of magnitude higher than that of $D$. galeata. On the two sampling dates after the storm, the density of $D$. hyalina has increased by more than a factor of three and the density of $D$. galeata has strongly declined.
Fig. 5 (a) and (b) show high-resolution temperature records (10 s sampling interval) measured at 8 and $4 \mathrm{~m}$ depth on top of the NDP before (23-25 August) and after (9-11 October) the wind event, respectively. Panels (c) and (d) show the corresponding diurnal distribution pattern of fish as estimated from the NDP
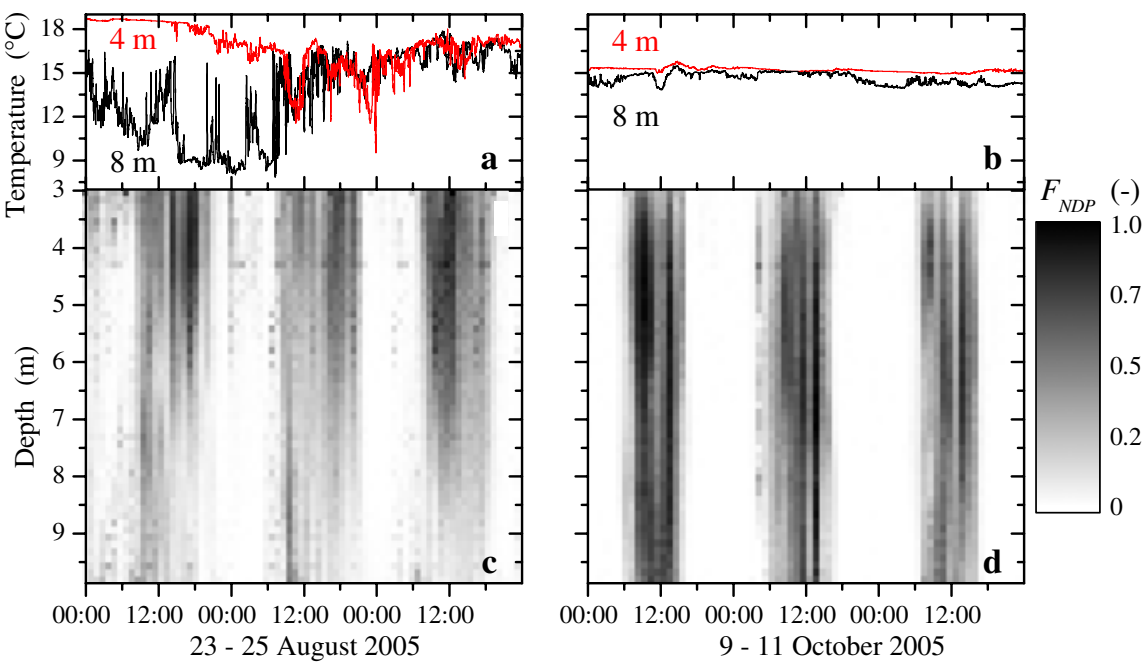


\section{Discussion}

The zooplankton community in Lake Constance during the time period of investigation (AugustNovember) is, in terms of biomass, dominated by Daphnia (Straile \& Geller, 1998). Correlation analysis of acoustic backscatter at $600 \mathrm{kHz}$ and zooplankton abundance estimated from net hauls during former studies at Lake Constance revealed that the backscatter signal is predominantly determined by the abundance of Daphnia (Wolf et al., 2005). Two different species of Daphnia were observed in the lake-D. hyalina and D. galeata (Geller, 1986). D. hyalina shows a pronounced diel vertical migration between May and November, whereas D. galeata remains near the surface (Stich \& Lampert, 1981; Einsle, 1988). Although during fall the abundance of the nonmigrating $D$. galeata is usually lower than that of $D$. hyalina in the pelagic zone (Fig. 3e), the latter migrating species has to overcome the horizontal distance of about $500 \mathrm{~m}$ between the study site in the littoral and the contour line marking a depth of $50 \mathrm{~m}$, below which they stay during daytime. Although zooplankton data are available only from a pelagic sampling site relatively far away from our littoral sampling site, they will be used for a qualitative discussion of our observations. The acoustically observed relative zooplankton concentration $S_{z o o}$ shown in Fig. 3d can be related to the dynamics of both Daphnia species. $S_{z o o}$ remained more or less constant until the wind event and the backscatter signal was dominated by $D$. galeta. If migrating $D$. hyalina were present during the night, they added only a small amount to $S_{z o o}$ because it represents a logarithmic measure of the zooplankton concentration. After the wind event, however, the abundance of D. galeata and hence $S_{z o o}$ decreased gradually and the nighttime contribution of $D$. hyalina to $S_{z o o}$ became more pronounced, leading to a clear diurnal pattern in $S_{z o o}$. A second maximum of the abundance of $D$. hyalina in October was also observed during other studies at Lake Constance (Wang \& Eckmann, 1994).

The detailed view of the diurnal pattern of $S_{z o o}$ provided by Fig. 6 shows a gradual increase over night and a rapid decrease before dawn. This sawtooth like dynamics can be explained by the vertical migration of $D$. hyalina from depths below $50 \mathrm{~m}$ and a relatively slow horizontal transport from the pelagic into the littoral zone. Whether this horizontal movement is caused by active swimming or by passive advection and dispersion of the zooplankton distribution remains unclear.

The fish community at the same artificial reef was studied in 2004 by scuba divers and by underwater stereo photography (A. Weber, unpublished data). This study revealed that the artificial reef is mainly inhabited by two different species: whereas the juvenile ruffe can be found deep within the brushwood, juvenile (0+) perch aggregate in dense shoals above and around the artificial reef, indicating that our observed relative fish counts $F_{N D P}$ are predominantly related to the latter species. The observations in 2004 showed a dramatic increase in perch abundance during September and October with maximum fish densities of more than $250 \mathrm{~m}^{-3}$. In excellent accordance with these findings from optical observation, $F_{N D P}$ increased substantially during the same months (cf. Fig. 3). A similar increase in the abundance of perch in fall was also described by Wang and Eckmann (1994) as well as by Imbrock et al. (1996), who studied the seasonal behavior of perch in Lake Constance in detail. According to both studies, juvenile perch spend the summer within macrophyte patches in the shallow littoral zone, which provide not only food resources but also shelter and shade. With progressing senescence of the macrophytes in autumn, the fishes are moving toward the deeper littoral zone, where they form dense shoals, preferably in close proximity to complex underwater structures like ports or, as in our case, artificial reefs. During that time period, they perform a pronounced diel activity pattern, whereby they stay within the upper part of the water column during daytime and spend the darkness resting close to the bottom. During October the fishes are moving out of the littoral into the profundal zone where they spend the winter (Imbrock et al., 1996). The complete behavioral cycle is evident in the time series of $F_{N D P}$ shown in Fig. 3 and 4, whereas the diurnal pattern in $F_{N D P}$ can be explained by vertical migration of the fish to depths below the measurement range of our instrument which did not cover the bottom $2.5 \mathrm{~m}$ above the sediment.

Wang and Eckmann (1994) and Imbrock et al. (1996) observed that the migration of perch from the shallow to the deeper littoral zone was associated with strong wind events. The authors assumed that 
the actual trigger of this migration was a drop in water temperature following the wind event. Our data, however, do not really show such a temperature drop after the wind event, but rather suggest that temperature variance is an important factor associated with the increase of fish abundance $F_{N D P}$ at our measuring site. The increase in $F_{N D P}$ is assumed to result from perch that migrate from the shallow littoral zone to our measuring site in the deep littoral. Strong temperature variance on rather short time scales (minutes to hours), however, seems not to affect the distribution or behavior of the fishes (Fig. 5).

The most interesting aspect of our observations is the simultaneous observation of the dynamics of zooplankton and fish abundance in relation to environmental factors. The wind event on September 18 led to a deepening of the surface mixed layer and to a significant reduction of temperature variance between 3 and $10 \mathrm{~m}$ depth. Following this wind event, dense shoals of juvenile perch could be observed at the study site in the deep littoral zone and the littoral zooplankton concentration, which at this time was dominated by nonmigrating $D$. galeata, started to decrease gradually. It can be expected that this decrease in zooplankton concentration is, at least partially, related to the presence of dense shoals of perch. With decreasing concentrations of D. galeata, the zooplankton population becomes increasingly dominated by $D$. hyalina, who perform a diel vertical migration and who can reach the study site by active or passive horizontal movement only. As a consequence, the zooplankton concentration at the study site is high only during the night when perch is inactive (perch is a visually-oriented predator; Schleuter and Eckmann (2006) have demonstrated in laboratory experiments that feeding success of perch is reduced significantly during darkness). Thus, as illustrated in Fig. 6, we observed an opposing diurnal activity pattern of predator and prey, which significantly constrains feeding of juvenile perch on $D$. hyalina to the hours around sunset and sunrise, respectively. The potential food limitation of perch eventually triggered their migration from the littoral into the profundal zone, where they stay over winter.

Acknowledgments We thank B. Rosenberg, J. Halder and the scientific diving team at the Limnological Institute of the University of Konstanz for their great help in the field.
D. Straile kindly provided the zooplankton data. This study was financially supported by the German Research Foundation (grant LO 1150/2-2 to AL and within the Collaborative Research Center 454: The littoral zone of Lake Constance).

\section{References}

Bassett, C. E., 1994. Use and evaluation of fish habitat structures in lakes of the eastern United States by the USDA forest service. Bulletin of Marine Science 55: 1137-1148.

Burks, R. L., D. M. Lodge, E. Jeppesen \& T. L. Lauridsen, 2002. Diel horizontal migration of zooplankton: costs and benefits of inhabiting the littoral. Freshwater Biology 47: 343-365.

Davies, J., 1985. Evidence for a diurnal horizontal migration of Daphnia hyalina lacustris Sars. Hydrobiologia 120: 103-105.

Einsle, U., 1988. The long-term dynamics of crustacean communities in Lake Constance (Obersee, 1962-1986). Schweizerische Zeitschrift für Hydrologie 50: 136-165.

Folt, C. L. \& C. W. Burns, 1999. Biological drivers of zooplankton patchiness. Trends in Ecology \& Evolution 14: 300-305.

Gaedke, U., 1998. The response of the pelagic food web to re-oligotrophication of a large and deep lake (L. Constance): evidence for scale-dependent hierarchical patterns? Archiv für Hydrobiologie Special Issues Advances in Limnology 53: 317-333.

Geller, W., 1986. Diurnal vertical migration of zooplankton in a temperate lake (L. Constance): a starvation avoidance mechanism? Archiv für Hydrobiologie Supplement 74: $1-60$.

Gliwicz, M. Z., 1986. Predation and the evolution of vertical migration in zooplankton. Nature 320: 746-748.

Hülsmann, S., T. Mehner, S. Worischka \& M. Plewa, 1999. Is the difference in population dynamics of Daphnia galeata in littoral and in pelagic areas of a long-term biomanipulated reservoir affected by age- 0 fish predation? Hydrobiologia 408/409: 57-63.

Imbrock, F., A. R. Appenzeller \& R. Eckmann, 1996. Diel and seasonal distribution of perch in Lake Constance: a hydroacoustic study and in situ observations. Journal of Fish Biology 49: 1-13.

Järvalt, A., T. Krause \& A. Palm, 2005. Diel migration and spatial distribution of fish in a small stratified lake. Hydrobiologia 547: 197-203.

Lampert, W., 1993. Ultimate cause of diel vertical migration of zooplankton: new evidence for the predator-avoidance hypothesis. Archiv für Hydrobiologie Special Issues Advances in Limnology 39: 79-88.

Löffler, H., 1997. Artificial habitats for fishes in Lake Constance (Bodensee): observation of fish aggregating devices with a remotely operated vehicle. Fisheries Management and Ecology 4: 419-420.

Lorke, A., D. F. McGinnis, P. Spaak \& A. Wüest, 2004. Acoustic observations of zooplankton in lakes using a Doppler current profiler. Freshwater Biology 49: 1280-1292. 
Lorke, A., F. Peeters \& E. Bäuerle, 2006. High-frequency internal waves in the littoral zone of a large lake. Limnology and Oceanography 51: 1935-1939.

Lorke, A. \& A. Wüest, 2005. Application of coherent ADCP for turbulence measurements in the bottom boundary layer. Journal of Atmospheric and Oceanic Technology 22: $1821-1828$.

Martin, A. P., 2003. Phytoplankton patchiness: the role of lateral stirring and mixing. Progress in Oceanography 57: 125-174.

Masson, S., N. Angeli, J. Guillard \& B. Pinel-Alloul, 2001. Diel vertical and horizontal distribution of crustacean zooplankton and young of the year fish in a sub-alpine lake: an approach based on high-frequency sampling. Journal of Plankton Research 23: 1041-1060.

Pinel-Alloul, B., 1995. Spatial heterogeneity as a multiscale characteristic of zooplankton community. Hydrobiologia 300/301: 17-42.

Prince, E. D. \& O. E. Maughan, 1978. Freshwater artificial reefs: biology and economics. Fisheries 3: 5-9.

Rogers, K. B. \& E. P. Bergersen, 1999. Utility of synthetic structures for concentrating adult northern pike and largemouth bass. North American Journal of Fisheries Management 19: 1054-1065.

Romare, P., S. Berg, T. Lauridsen \& E. Jeppesen, 2003. Spatial and temporal distribution of fish and zooplankton in a shallow lake. Freshwater Biology 48: 1353-1362.
Ruiz, G. M., A. H. Hines \& M. H. Posey, 1993. Shallow water as a refuge habitat for fish and crustaceans in non-vegetated estuaries: an example from Chesapeake Bay. Marine Ecology Progress Series 99: 1-16.

Schleuter, D. \& R. Eckmann, 2006. Competition between perch (Perca fluviatilis) and ruffe (Gymnocephalus cern$u u s)$ : the advantage of turning night into day. Freshwater Biology 51: 287-297.

Stich, H.-B. \& W. Lampert, 1981. Predator evasion as an explanation of diurnal vertical migration by zooplankton. Nature 293: 396-398.

Straile, D. \& W. Geller, 1998. Crustaceen zooplankton in Lake Constance from 1920 to 1995: response to eutrophication and re-oligotrophication. Archiv für Hydrobiologie Special Issues Advances in Limnology 53: 225-274.

Wang, N. \& R. Eckmann, 1994. Distribution of perch (Perca fluviatilis L.) during their first year of life in Lake Constance. Hydrobiologia 277: 135-143.

White, M. D., 1998. Horizontal distribution of pelagic zooplankton in relation to predation gradients. Ecography 21: 44-62.

Wolf, T., H.-B. Stich \& A. Lorke, 2005. Determination of Spatial Distribution Patterns and Diurnal Vertical Migration of Zooplankton in Lake Constance by Acoustic Backscatter. Jahrestagung der Deutschen Gesellschaft für Limnologie, Karlsruhe. 